\title{
Possibilities of Use Recycled Materials in Construction Details
}

\author{
Radim Smolka ${ }^{1, *}$, and Jindřich Sobotka ${ }^{1}$ \\ ${ }^{1}$ Brno University of Technology, Faculty of Civil Engineering, \\ Institute of Building Structures, Veveří 95, 60200 Brno, Czech Republic
}

\begin{abstract}
This paper aims to explain the use of secondary materials in design details. Primarily, attention is paid to flat roofs, for which there is currently a wide range of technologies needed for user-friendly operation of a building. Recycled materials are still often looked down on and, therefore, it is important to show that even these elements may work very well in constructions. They must meet strict criteria for static and thermal properties. Furthermore, they must comply with fire and weather resistance requirements. They also have acoustic, secondary and aesthetic function. The roof structure is one of the basic segments that characterize the final properties of the building. Any malfunctions will lead to increased economic costs and degradation of users' environment.
\end{abstract}

\section{Introduction}

Effective legislation, government decrees of the Czech Republic, and EU membership bring about requirements for reducing energy consumption. Therefore, civil engineering industry is forced to find and develop new construction elements and construction technologies. During designing and construction of energy-efficient houses, passive houses, and nearly zero energy houses thus leads to many problematic viewpoints, which need to be dealt with in situ.

Taking over tested details and elements from other countries is not desirable due to different climatic conditions in the Czech Republic. In addition, it is necessary to deal with the issue of community and corporate waste. Therefore, connecting civil engineering with a potential to integrate waste secondary materials seems obvious. The most used is the waste from demolition works (e.g. debris), asphalt waste from road reconstructions, and plastic materials.

Community waste can be divided into sorted and unsorted (currently, mainly two types of glass, plastic - mostly unsorted, in some cases strictly sorted, e.g. PET bottles and paper). Electric waste and fabric containers begin to appear. Plastic secondary material is technologically and economically more demanding to recycle and unsuitable to be reused in food industry.

\footnotetext{
*Corresponding author: smolka.r@ffce.vutbr.cz
} 


\section{Potential use of recycled materials in construction details}

Flat roofs begin to be more and more equipped with technological devices which cannot be placed inside structures due to space, financial and operational constraints. Therefore, some more requirements need to be met regarding the composition of the roof layer The technology is in most cases heavier and the maintenance of the technology means higher frequency of movement on the roof.

Requirements on elements:

- long life span,

- frost resistance,

- constant volume,

- tolerance of other materials (material corrosion),

- strength - resistance to impacts and constant load,

- fast and all-year-round construction without technological changes,

- meeting requirements for fire resistance.

All the above mentioned properties are required for proper function and long-term life span of the designed product $[1,2]$.

\subsection{Classification of current critical details}

\subsubsection{Example 1}

Regarding the existing technology process, the distributing layer is produced directly on the waterproof roof layer (Fig. 1, 2). A concrete block is used as a relatively good distributing element, but creates an obstacle to draining water. Subsequently, it is very difficult to make spreading wedges and divert water out of exposed areas.
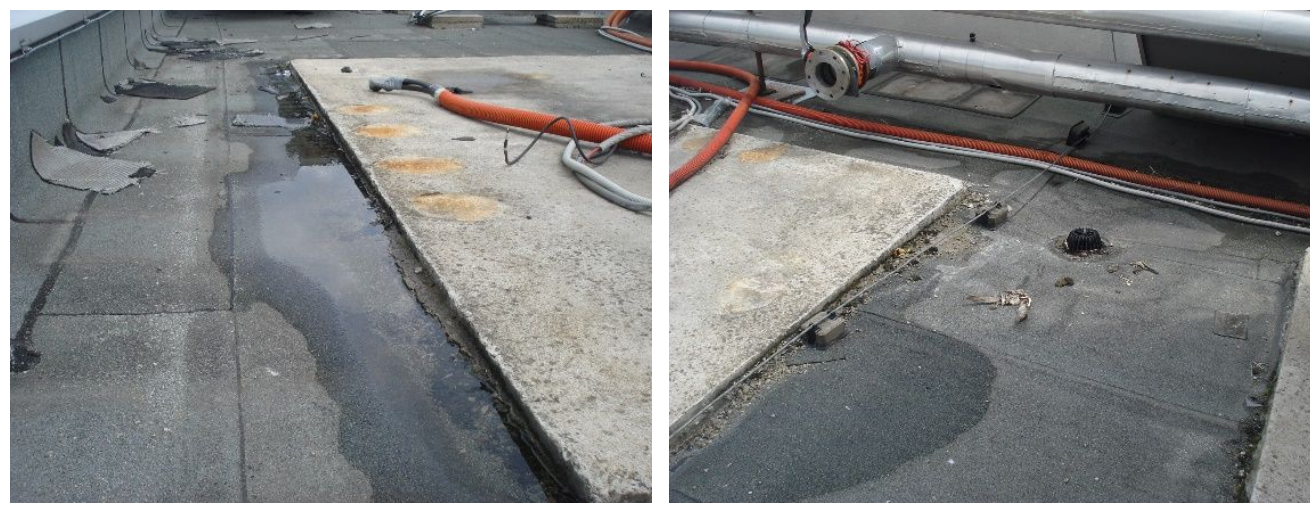

Fig. 1, 2. Pushing of distributing concrete structure to roof cladding

If a thermal insulator, which does not have a sufficient compressive strength, is used, the thermal insulator is locally compressed and creates depressions with water. The risk is a damaged distributing layer as well as higher chance of damage to the waterproof layer and subsequent leakage.

Figures above show a clear effect of unsuitably selected distributing structure under the technological device. Water stays in the place of compression and the roof drain, placed between the boards, is unable to drain the water. 


\subsubsection{Example 2}

Another option is to use point support of technological devices. The requirements for bearing capacity of the lower material is higher, but the drainage of water out the roof structure is ensured. However, local depression occurs as well and the point support may lead to higher risk of local damage to the waterproofing layer.
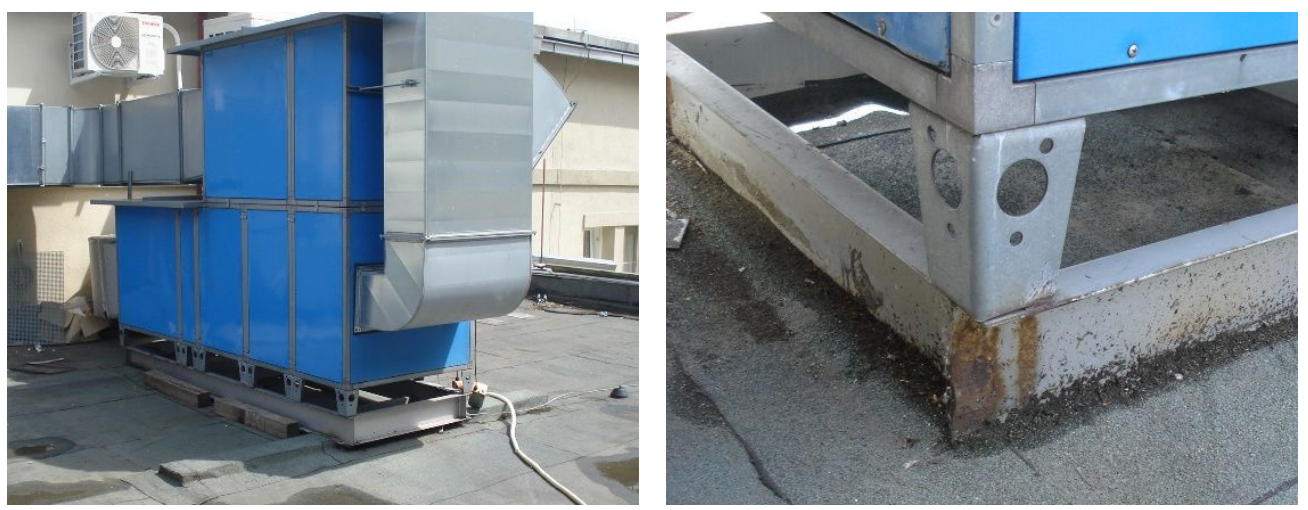

Fig. 3, 4. Technological device on band supports and detail support

However, when older structures were designed no other use was considered in advance, e.g. installation of air-treatment and air-conditioning units $[3,4,5]$.

\subsubsection{Example 3}

Recently, in places where technological devices are to be installed on roof structures in the future, thermal insulation materials with higher compression strength are applied in the composition of the roof cladding. In case producer's complete assortment is used, it is just a matter of technological discipline to place all distributing thermal insulation boards properly.

In case higher compression strength is needed, when the distributing structure is missing, materials are combined to reach financial savings. In those cases more materials are used with different technological conceptions and complicated measures are made.

One of the options is to use lower thickness thermal insulator and subsequent application of a distributing layer /concrete structure). The limiting factor is a local decrease of the heat conductivity coefficient in the roof layers. In order to reach roof gradient without installed barriers at the minimum required thickness of the thermal insulator, general height of the roof structure increases.

\subsection{Application of plastic in flat roofs}

The following chapter describes and checks optional application of secondary plastic materials in construction details. The element is considered to be placed on the surface as well as at the end detail, e.g. at the attic. Safe connection of an inserted element with the waterproof layer is an integral part of the detail function.

According to the above mentioned drawbacks, main points of a new product for civil engineering are set. The product, while keeping the required flat roof gradient, should transfer balanced loading to heat insulating underlayers or be used as a substitute to a common thermal insulator. Furthermore, it should allow simple and safe installation of waterproof layers, without a change in technological specifications. The application of this 
product should be possible in new buildings (standard, passive, and energy-efficient buildings), as well as in the existing buildings during reconstructions and construction works, mostly during renovation works.

The following basic properties the element should have are considered:

- long life span,

- constant volume,

- tolerance of other materials (material corrosion),

- strength - resistance to impacts and constant load,

- fast and all-year-round construction without technological changes,

- meeting requirements for fire resistance,

- harmless to health,

- sound insulation.

The above mentioned properties are required for proper function and long-term life span of the designed product $[6,7,8]$.

\section{Conclusion}

The design concerns the below described construction detail of a roof cladding with potential application to other details that are on the roof cladding.

The performed test of peeling in joints confirmed placement of plastic boards in construction details of roof structures.

Checking:

a)potential local joining,

b)potential all-area setting.

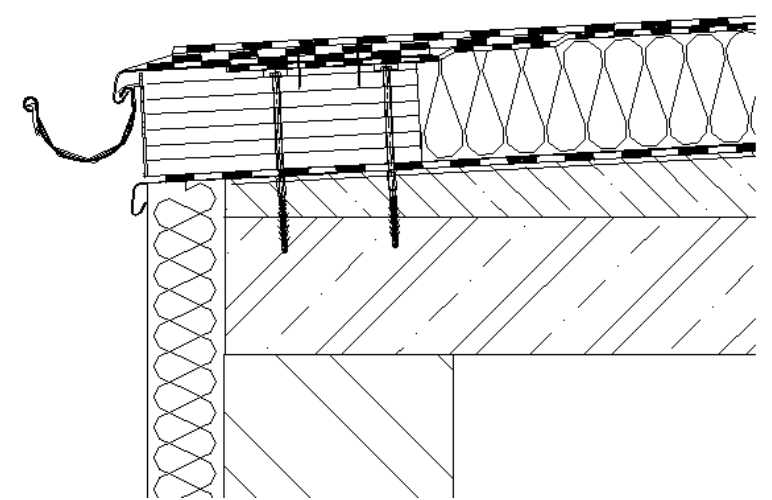

Fig. 5. Scheme of construction detail at the gutter - local joining

Local joining (Fig. 5) to boards from secondary materials is suitable for construction details of end elements on the roof cladding. Suitable use is in the corners at the attic, at the end of the structure at the light well, at roof hatches, etc. The inserted board is firm and its thermal insulation properties can replace standard inserted elements, such as extruded polystyrenes with the cover layer of OSB boards. 


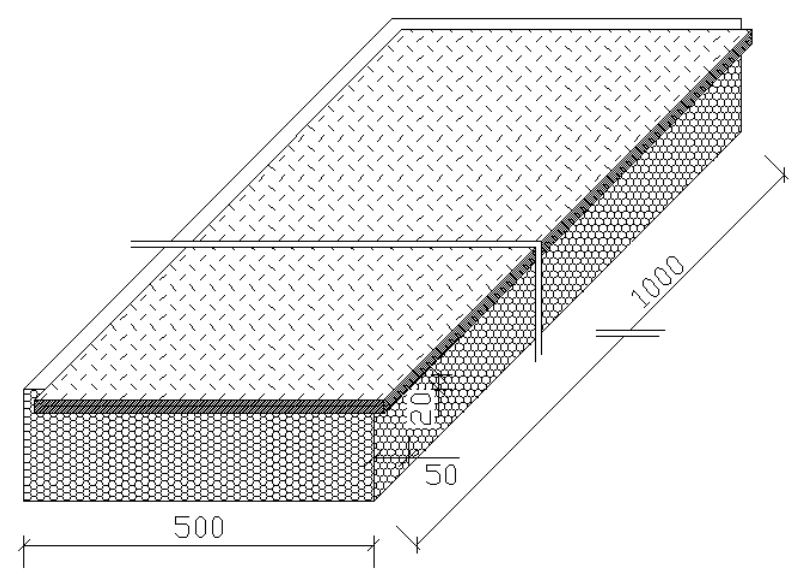

Fig. 6. Designed board for full-area setting

A heat insulation element with a integrated layer from a plastic board (Fig. 6) is designed for larger areas. The board is applied on the thermal insulator with an overlap of $50 \mathrm{~mm}$ off the area. The element is thus firmly fitted and loading is evenly distributed to other elements. This system is useful under technological devices on the roof cladding.

This paper has been produced within the project No. LO1408 "AdMaS UP - Advanced Materials, Structures and Technologies", supported by Ministry of Education, Youth and Sports under the "National Sustainability Programme I".

\section{References}

1. L. Matejka, R. Smolka, Support structures for a doors threshold (2012)

2. V. Duchacek, Polymers - production, properties, processing, applications, 274 (2006)

3. ČSN EN 12316-1 (727638), Waterproofing strips and foils - Part 1: Bitumen bands for roof waterproofing - Determination of buckling resistance in couplings. Prague: Office for Standardization, Metrology and State Testing (2000)

4. J. Sobotka, Trans Tech Publications (2015)

5. R. Smolka; J. Sobotka, MATEC Web Conferences, 146, 02009 (2018)

6. P. Kacálek, R. Smolka, T. Petř́iček, Trans Tech Publications (2014)

7. T. Petříček, P. Kacálek, R. Smolka, Trans Tech Publications (2014)

8. T. Petříček, P. Kacálek, MATEC Web of Conferences, 146, 02017 (2018) 